\title{
PRE-FAILURE INSTABILITY BEHAVIOR OF SAND IN STRAIN PATH TESTING UNDER PLANE-STRAIN CONDITIONS
}

\author{
D. WanatowsKi ${ }^{\mathrm{i})}$ and J. ChU ${ }^{\mathrm{ii})}$
}

\begin{abstract}
Experimental data are presented in this paper to study the instability behavior of sand in strain path testing under plane-strain conditions. $K_{0}$ consolidated strain path tests were conducted on Changi sand using a plane-strain apparatus. The test results show that the occurrence of pre-failure instability under plane-strain conditions is affected by the void ratio and the strain increment ratio. This is consistent with previous findings established under axisymmetric conditions. However, instability behavior of medium dense sand in strain path-controlled plane-strain tests can also be affected by shear band formation. In this case, on-failure instability takes place and failure is likely caused by shear band development. This observation is different from that in triaxial strain path-controlled tests where shear bands do not normally occur.
\end{abstract}

Key words: failure, granular material, laboratory test, plane strain, pore pressure (IGC: D6)

\section{INTRODUCTION}

Failure of geotechnical structures can be initiated by instability of soil. The term instability as used in this paper refers to a behavior in which large plastic strains are generated rapidly due to the inability of a soil element to sustain a given load or stress. Instability is normally considered to have taken place when the stress state of a soil element satisfies a failure criterion, as in the conventional stability analysis. However, instability may also occur prior to attaining the failure stress state. A typical example is static liquefaction which occurs before the effective stress path reaches the failure line (which is also the steady state line for loose sand). So far, this so called pre-failure instability has been observed mainly for saturated loose sand under undrained conditions (Lade et al., 1988; Lade and Pradel, 1990; Leong et al., 2000, Wanatowski and Chu, 2007). However, the undrained condition may not be necessary. There are failure cases that occurred under fully drained or other than undrained conditions (Torrey and Weaver, 1984; Eckersley, 1985; Olson et al., 2000; Adalier and Elgamal, 2002; Sento et al., 2004). The failure mechanisms related to the re-distribution of void ratio within a globally undrained sand layer (Fig. 1(a)) or spreading of excess pore water pressure with global volume changes along a slope (Fig. 1(b)) have been suggested by the U.S. National Research Council (NRC, 1985). Adalier and Elgamal (2002) also observed from a series of centrifuge model tests that there is a potential strength loss in dense sand as a result of pore water migration into the dense zone from the adja-

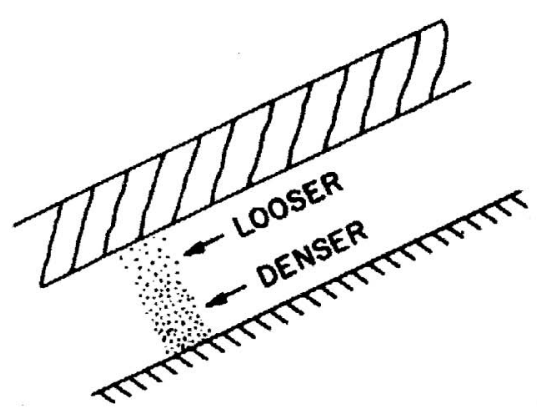

(a)

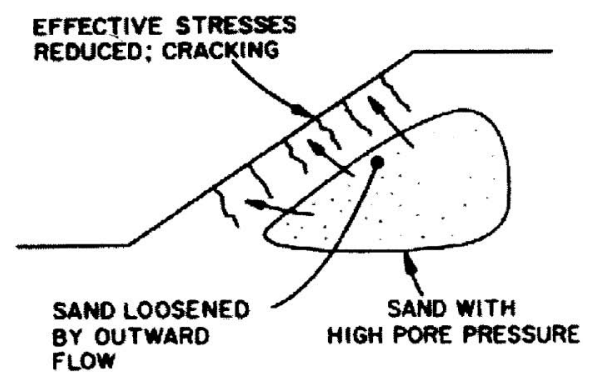

(b)

Fig. 1. Failure mechanisms defined by NRC: (a) mechanism B: simulation for void redistribution within a globally sand layer; (b) mechanism $C$ : situation for failure by spreading of excess pore pressure with global volume changes (after NRC, 1985)

cent loose zone in the ground. This further indicates that flow slides can also take place under other than undrained conditions. These, other than undrained or the so-called

i) Lecturer, University of Nottingham, United Kingdom (dariusz.wanatowski@nottingham.ac.uk).

ii) Associate Professor, Nanyang Technological University, Singapore (cjchu@ntu.edu.sg).

The manuscript for this paper was received for review on August 24, 2009; approved on February 7, 2011.

Written discussions on this paper should be submitted before January 1, 2012 to the Japanese Geotechnical Society, 4-38-2, Sengoku, Bunkyoku, Tokyo 112-0011, Japan. Upon request the closing date may be extended one month. 
non-undrained conditions (Chu et al., 1992), have been simulated in the laboratory under axisymmetric conditions by the use of a strain path testing method (Chu and Lo, 1991), in which the strain increment ratio, $d \varepsilon_{\mathrm{v}} / d \varepsilon_{1}$, imposed to a specimen, is controlled. When $d \varepsilon_{\mathrm{v}} / d \varepsilon_{1}>0$, the soil specimen compresses and when $d \varepsilon_{\mathrm{v}} / d \varepsilon_{1}<0$, the specimen dilates. An undrained test is only a special case when $d \varepsilon_{\mathrm{v}} / d \varepsilon_{1}=0$. The strain path method also provides a better simulation of the field situations, where a soil element will normally experience both volume change and pore water pressure changes simultaneously and fully drained or undrained conditions are only exceptional cases.

The use of strain path testing method to study prefailure instability behavior of granular soils is uncommon (Chu et al., 1993; Vaid and Eliadorani, 1998, Chu and Leong, 2001; Lancelot et al., 2004; Sivathayalan and Logeswaran, 2007) even though pre-failure instability is often associated with the progressive failure of sandy slopes. Chu et al. (1993) proposed a comparison of $d \varepsilon_{\mathrm{v}}$ $/ d \varepsilon_{1}$ imposed to the specimen with the maximum dilation rate at failure, measured by $d \sigma_{3}^{\prime}=0$ test, as the criterion for the occurrence of instability. Chu and Leong (2001) conducted a number of tests on loose and dense granular materials under strain path controlled conditions. They observed a large reduction in the shear resistance and runaway flow failure after instability occurred. Similar experimental studies were carried out by Vaid and Eliadorani (1998), Lancelot et al. (2004) and Sivathayalan and Logeswaran (2007). It was reported that the small expansive volumetric strains resulting from the strain path controlled condition could render an initial state that would have been stable in an undrained test into an unstable state. Therefore, an undrained condition, commonly assumed as the most conservative, might not be the most dangerous situation for a granular soil slope.

It needs to be pointed out that all of the above cited studies under strain path controlled conditions have been carried out under axisymmetric conditions using triaxial cells. However, slopes can only be idealized into planestrain or three-dimensional stress conditions. Although several studies on the behavior of sand under plane-strain conditions have been carried out (e.g., Cornforth, 1964; Tatsuoka et al., 1986; Han and Vardoulakis, 1991; Finno et al., 1996; Yasin et al., 1999; Desrues and Viggiani, 2004), the data on pre-failure instability under planestrain conditions are still very limited. Furthermore, to authors' knowledge, no study on the pre-failure instability behavior of sand using strain path testing method has been conducted under plane-strain conditions Therefore, to apply the triaxial results to a plane-strain condition, one would have to address questions such as what are the differences between instability occurring under axisymmetric and plane-strain conditions, whether the instability behavior observed under the axisymmetric condition can be directly applied to the plane-strain conditions and whether the conditions for instability to occur under triaxial conditions are the same as those under planestrain conditions.
The objective of this paper is to study the pre-failure instability of sand in strain path testing under planestrain conditions and to address the questions raised above. The results of the strain path tests conducted on very loose to medium dense sand are presented. Various factors affecting the occurrence of pre-failure instability under plane-strain conditions are analyzed and discussed. Conditions for the occurrence of pre-failure instability are established. Comparison of pre-failure instability under triaxial and plane-strain conditions is made. Differences and similarities between instability behaviors under axisymmetric and plane-strain conditions are pointed out.

\section{TEST ARRANGEMENT}

The plane-strain test system developed by Wanatowski and Chu (2006) was used in this study. A schematic diagram of the testing system is shown in Fig. 2. A prismatic soil specimen of $120 \mathrm{~mm}$ in height and $60 \times 60 \mathrm{~mm}$ in cross-section was tested. Two $35 \mathrm{~mm}$ thick rigid vertical platens were fixed in position by two pairs of horizontal tie rods to impose a plane-strain condition. The lateral stress in this direction $\left(\sigma_{2}\right)$ was measured by four submersible total pressure transducers. Two transducers were used for each platen, so that the lateral pressures at both the top and the bottom positions of the specimen could be measured and any non-uniform stress distribution could be detected. The total lateral pressure was evaluated as an average value obtained from the four individual transducers. All rigid platens were properly enlarged and lubricated using a free-end technique (Rowe and Barden, 1964) to reduce the boundary frictions and to delay the

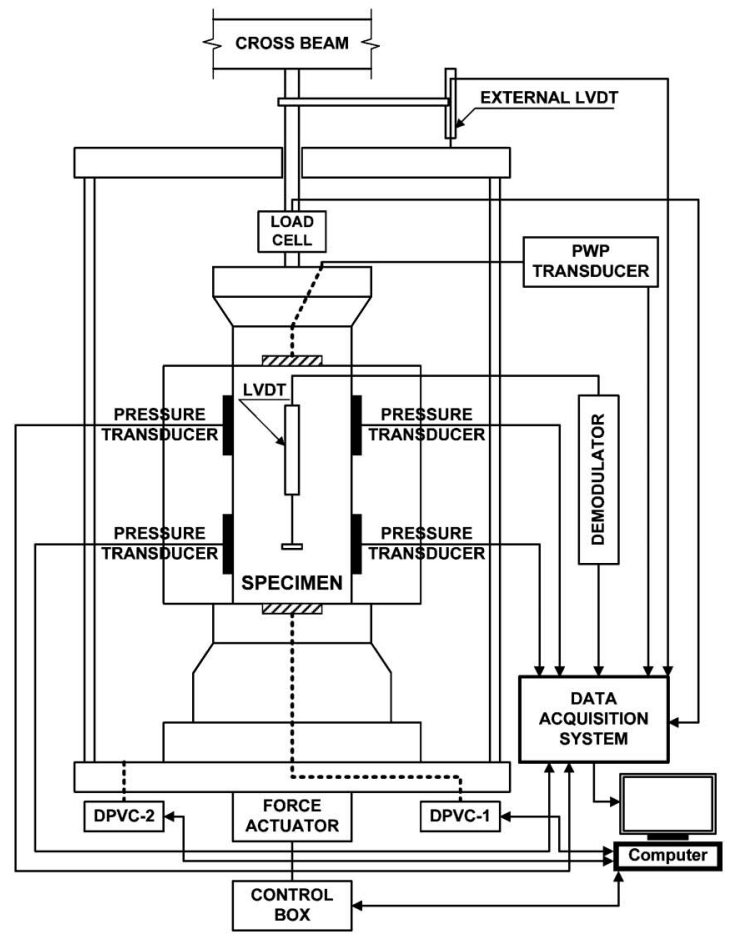

Fig. 2. Schematic diagram of the testing system 
occurrence of non-homogeneous deformations. For the top and base platens, latex discs were used whereas for the two vertical platens, Teflon sheets were adopted. A pair of miniature submersible linear variable differential transformers (LVDT) was used to measure the vertical displacement. An external LVDT was also used to measure the axial strain when the internal LVDTs ran out of travel. A digital hydraulic force actuator was mounted at the bottom of a loading frame to apply axial load. The actuator comprised a stepping motor and gearbox that slides on a linear guide. The actuator could control a desired rate of load or rate of displacement directly using a computer via a digital load/displacement control box. A $10 \mathrm{kN}$ submersible load cell was used to measure the vertical load. The cell pressure was applied through a digital pressure/volume controller (DPVC). Another DPVC was used to control the back pressure from the bottom of the specimen while measuring the volumetric change at the same time. A pore pressure transducer was also used to record the pore water pressure at the top of the specimen. For details of the plane-strain apparatus, see Wanatowski and Chu (2006).

\section{MATERIAL TESTED}

The granular soil tested in this study was a marine dredged silica sand, the so-called Changi sand, used for the Changi land reclamation project in Singapore (Leong et al., 2000). The Changi sand has the specific gravity $\left(G_{\mathrm{s}}\right)$ of 2.60 , the mean grain size $\left(D_{50}\right)$ of $0.30 \mathrm{~mm}$, the coefficient of uniformity $\left(C_{\mathrm{u}}\right)$ of 2.0 , and the coefficient of curvature $\left(C_{\mathrm{c}}\right)$ of 0.8 . The fines' content is approximately $0.4 \%$. According to Unified Soil Classification System (ASTM D2487-06) it is medium grained, poorly graded, clean sand. The individual particles of the sand are mainly subangular in shape. The minimum and maximum void ratios were 0.533 and 0.916 , respectively. The minimum void ratio $\left(e_{\min }\right)$ was determined according to ASTM D 4253-00 and the maximum void ratio $\left(e_{\max }\right)$ according to ASTM D 4254-00. Since the Changi sand is dredged from the seabed, it contains shells of various sizes ranging from 0.2 to $10 \mathrm{~mm}$. The shell content of the Changi sand is approximately $12 \%$.

\section{SPECIMEN PREPARATION AND TESTING PROCEDURES}

Laboratory reconstituted specimens were used in this study. Two different specimen preparation methods, the water sedimentation (WS) and the moist tamping (MT) were employed. A four-part split mould was used for the preparation of all the specimens. A $0.4 \mathrm{~mm}$ thick latex membrane was fitted into the mould. A vacuum pressure of $10 \mathrm{kPa}$ was used to achieve a tight fit between the mould and the membrane. In the WS method, sand was pluviated into the mould which was half-filled with deaired water. Deposition of sand was done by moving the tip of the funnel in a circular motion $1-2 \mathrm{~cm}$ above the water surface. In the MT method, the oven-dried sand was first mixed with $5 \%$ of de-aired water. After mixing, the moist sand was deposited into the mould in five layers and each layer was compacted using a small tamper. To achieve a greater uniformity of specimens the undercompaction method, proposed by Ladd (1978) was used. For each layer, the compactive effort was increased towards the top with the undercompaction ratio of $2.5 \%$. For saturation, the specimen was flushed with de-aired water from the bottom to the top for 60 minutes under a water head of about $0.5 \mathrm{~m}$. After that a back pressure of 400 $\mathrm{kPa}$ was applied. The Skempton's pore water pressure parameter (B-value) greater than 0.96 was obtained for all the specimens. A liquid rubber technique (Lo et al., 1989) was adopted to reduce the bedding and membrane penetration errors. For more details of the sample preparation procedures see Wanatowski and Chu (2006).

All the specimens were consolidated from an initial isotropic stress state of $20 \mathrm{kPa}$ to the required stress state along the $K_{0}$ path. The $K_{0}$ condition was imposed by regulating the volume change of the specimen in accordance with the axial strain to maintain $d \varepsilon_{\mathrm{v}} / d \varepsilon_{1}=1$, a method proposed by Lo and Chu (1991). Shearing in all the tests was carried out using a strain path method with $d \varepsilon_{\mathrm{v}} / d \varepsilon_{1}=$ const (Chu and Lo, 1991). In the strain path method, when $d \varepsilon_{\mathrm{v}} / d \varepsilon_{1}>0$, the soil element is in compression and water flows out of the specimen. When $d \varepsilon_{\mathrm{v}} / d \varepsilon_{1}$ $<0$, the soil element is in dilation and water flows into the specimen. An undrained test, with $d \varepsilon_{\mathrm{v}} / d \varepsilon_{1}=0$, is only a special case of the $d \varepsilon_{\mathrm{v}} / d \varepsilon_{1}=$ const test. Since in a strain path test the volumetric change of the specimen was controlled, a change in pore water pressure occurred. This change in pore water pressure led to a change in effective confining stress.

In this study a $d \varepsilon_{\mathrm{v}} / d \varepsilon_{1}=$ const strain path was imposed on a soil specimen by controlling the volume change of the specimen via the DPVC in accordance with the measured axial deformation. All the tests were computer controlled. The control loop consisted of the following steps:

(1) compute the axial strain from the deformation measured by the pair of internal LVDTs,

(2) compute $\varepsilon_{\mathrm{v}}$ and hence the volume change to be imposed by the DPVC according to the required $d \varepsilon_{\mathrm{v}}$ $/ d \varepsilon_{1}$

(3) send signal to DPVC to target the required volume change,

(4) read all transducers, plot the strain path followed and the effective stress state, record stress-strain parameters and return to step (1).

The continuous plotting of the actual strain path and the effective stress state followed at step (4) enabled the detection of any out of control. Satisfactory control was achieved for all the tests.

Two types of strain path tests were carried out in this study. The first type, a deformation-controlled (DC) strain path test was carried out with either negative or positive strain increment ratio using a constant deformation rate of $0.05 \mathrm{~mm} / \mathrm{min}$. The second type, a load-controlled (LC) strain path test (so-called strain path instability test) was carried out with a negative strain increment 
Table 1. A summary of strain path tests conducted under plane-strain conditions

\begin{tabular}{|c|c|c|c|c|c|c|c|c|}
\hline Test No & Preparation Method $^{\mathrm{a}}$ & $d \varepsilon_{\mathrm{v}} / d \varepsilon_{1}$ imposed & Loading mode ${ }^{b}$ & $e_{\mathrm{c}}$ & $p_{\mathrm{c}}^{\prime}(\mathrm{kPa})$ & $q_{\mathrm{c}}(\mathrm{kPa})$ & Type of behavior & Shear band \\
\hline INSP01 & MT & -0.6 & $\mathrm{LC}$ & 0.898 & 198.8 & 175.1 & Unstable & No \\
\hline INSP02 & WS & -0.6 & $\mathrm{LC}$ & 0.754 & 199.2 & 191.9 & Unstable & No \\
\hline INSP04 & WS & -0.2 & $\mathrm{LC}$ & 0.760 & 190.4 & 180.7 & Unstable & No \\
\hline INSP06 & WS & -0.6 & $\mathrm{LC}$ & 0.685 & 200.7 & 211.8 & Unstable & Yes \\
\hline INSP07 & WS & -0.6 & $\mathrm{LC}$ & 0.692 & 200.6 & 213.9 & Unstable & Yes \\
\hline INSP10 & WS & -0.2 & $\mathrm{LC}$ & 0.681 & 200.0 & 213.1 & Stable & No \\
\hline INSP11 & WS & -0.6 & $\mathrm{LC}$ & 0.798 & 200.9 & 198.0 & Unstable & No \\
\hline SP05 & WS & -0.4 & $\mathrm{DC}$ & 0.677 & 198.2 & 220.3 & Hardening & Yes \\
\hline SP09 & WS & -0.6 & $\mathrm{DC}$ & 0.679 & 200.0 & 222.4 & Hardening & Yes \\
\hline SP10 & WS & -0.6 & $\mathrm{DC}$ & 0.754 & 202.0 & 203.5 & Softening & Yes \\
\hline SP13 & WS & -1.0 & $\mathrm{DC}$ & 0.682 & 201.5 & 210.7 & Softening & Yes \\
\hline SP17 & WS & +0.4 & $\mathrm{DC}$ & 0.682 & 200.5 & 227.3 & Hardening & No \\
\hline SP23 & WS & +1.0 & $\mathrm{DC}$ & 0.686 & 202.8 & 226.6 & Hardening & No \\
\hline SP28 & WS & -0.6 & $\mathrm{DC}$ & 0.750 & 880.4 & 918.6 & Softening & Yes \\
\hline U02 & WS & 0.0 & $\mathrm{DC}$ & 0.695 & 201.9 & 218.8 & Hardening & Yes \\
\hline
\end{tabular}

${ }^{\mathrm{a}} \mathrm{MT}=$ moist tamping; WS $=$ water sedimentation.

${ }^{\mathrm{b}} \mathrm{DC}=$ deformation-controlled loading mode; $\mathrm{LC}=$ load-controlled loading mode.

ratio and with the deviator (vertical) load kept constant. As mentioned earlier, both tests could be successfully controlled via a digital load/displacement control box.

A summary of the plane-strain tests conducted is given in Table 1. Please note that the abbreviation 'SP' in Table 1 indicates a deformation-controlled strain path test and 'INSP' indicates a load-controlled strain path test with the deviator (vertical) load kept constant.

In this study, the deviatoric stress $q$ and the mean effective stress $p^{\prime}$ are defined as

$$
\begin{aligned}
& q=\frac{1}{\sqrt{2}}\left[\left(\sigma_{1}-\sigma_{2}\right)^{2}+\left(\sigma_{2}-\sigma_{3}\right)^{2}+\left(\sigma_{3}-\sigma_{1}\right)^{2}\right]^{1 / 2} \\
& p^{\prime}=\frac{1}{3}\left(\sigma_{1}^{\prime}+\sigma_{2}^{\prime}+\sigma_{3}^{\prime}\right)
\end{aligned}
$$

where $\sigma_{1}, \sigma_{2}$, and $\sigma_{3}$ are major, intermediate, and minor principal stresses, respectively; and the prime refers to effective stress.

\section{STRESS-STRAIN BEHAVIOR OF SAND IN PLANE-STRAIN}

Typical stress-strain behavior of Changi sand in planestrain tests is demonstrated in Fig. 3, where the results of a series of strain path tests conducted on medium dense sand with different strain increment ratios, $d \varepsilon_{\mathrm{v}} / d \varepsilon_{1}$, ranging from +1.0 to -1.0 are presented. All the specimens were $K_{0}$ consolidated to $p_{\mathrm{c}}^{\prime}=200 \mathrm{kPa}$. The void ratios of specimens after $K_{0}$ consolidation, $e_{\mathrm{c}}$, were in the range of 0.677 to 0.695 , corresponding to relative densities $D r_{\mathrm{c}}=$ $58-62 \%$. Although all the specimens were in the narrow density range, different types of stress-strain behavior, mainly strain hardening and limited strain softening were observed. The response for more compressive (positive) strain paths was strongly strain hardening compared to that for more dilative (negative) strain paths. Therefore, for a given axial strain, the larger the strain increment ratio imposed the stiffer the stress-strain curve obtained, as shown in Fig. 3(a). It can also be seen from Fig. 3(a) that stress-strain curves for the strain paths with $d \varepsilon_{\mathrm{v}} / d \varepsilon_{1}>0$ are different from those with $d \varepsilon_{\mathrm{v}} / d \varepsilon_{1} \leq 0$. For the strain path tests with $d \varepsilon_{\mathrm{v}} / d \varepsilon_{1}>0$, only strain hardening behavior was observed. As shown in Fig. 3(a), peak state is not reached by any of the $d \varepsilon_{\mathrm{v}} / d \varepsilon_{1}>0$ paths before the termination of the test. There is no visible shear band either. For the strain paths within the range $-0.6 \leq d \varepsilon_{\mathrm{v}} / d \varepsilon_{1} \leq 0$ the strain hardening behavior is also observed. However, it is followed by the peak state and the strain softening behavior in the post-peak region. It should be pointed out that the peak deviatoric stress in these tests coincides with shear band formation. Consequently, banding softening behavior (Chu et al., 1996; Wang and Lade, 2001) is observed in $-0.6 \leq d \varepsilon_{\mathrm{v}} / d \varepsilon_{1} \leq 0$ paths. It should also be pointed out that banding softening or diffusion bifurcation could have possibly occurred in the $d \varepsilon_{\mathrm{v}} / d \varepsilon_{1}>0$ strain paths if the shearing was further continued. However, the lateral pressures $\left(\sigma_{2}\right)$ in these tests reached the capacity of the lateral pressure transducers. Thus, the $d \varepsilon_{\mathrm{v}} / d \varepsilon_{1}>0$ strain path tests had to be terminated. It is also shown in Fig. 3(a) that the limited strain softening was observed in the $d \varepsilon_{\mathrm{v}} / d \varepsilon_{1}=-1$ path test. In this test, a material strain softening initially occurred and then the phase transformation state (PT), characterized by the minimum value of mean effective stress in the $q-p^{\prime}$ space (see Fig. 3(c)), was reached. After that a strain hardening behavior was observed and eventually the banding strain softening occurred.

The excess pore water pressures developed in the tests are shown in Fig. 3(b). It can be seen that the larger strain increment ratio imposed, the more negative pore water pressure change. It is noted that the excess pore water pressure developed in an undrained test is not the largest, as often assumed. The pore water pressure generation for 


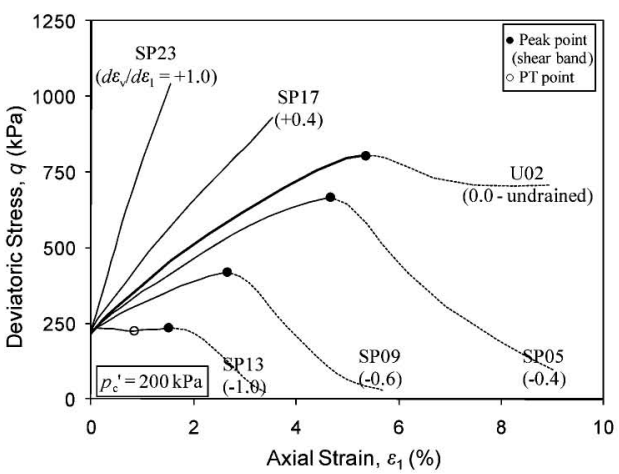

(a)

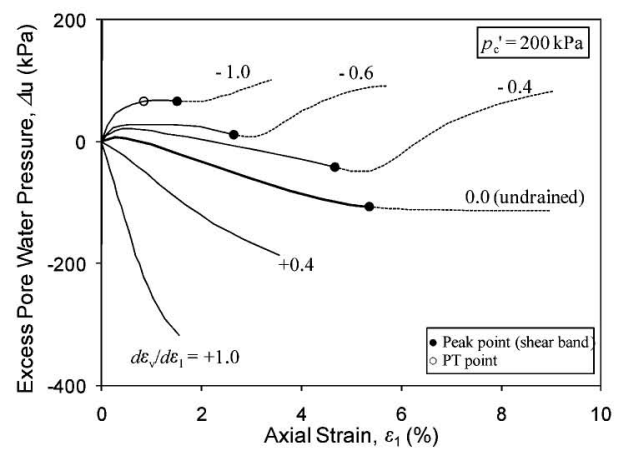

(b)

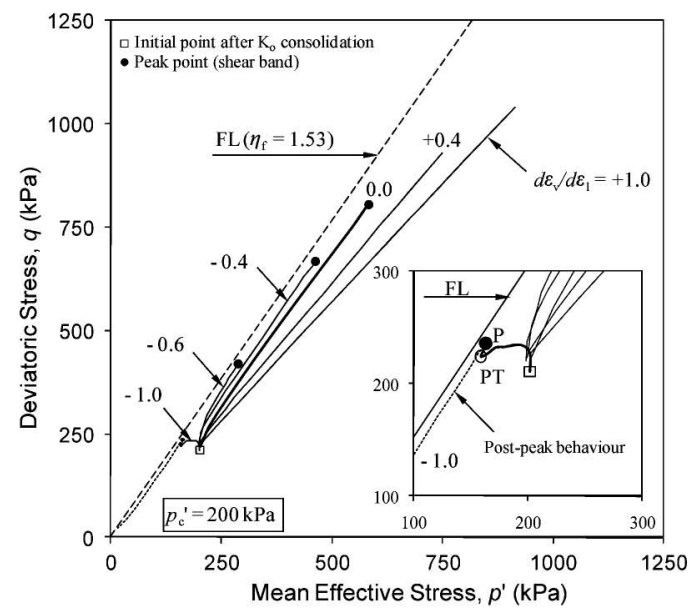

(c)

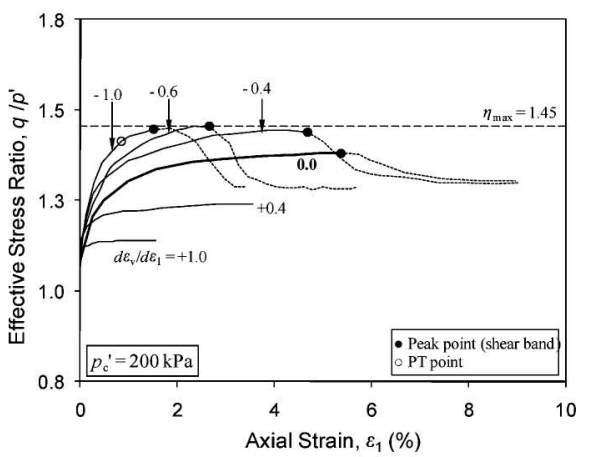

(d)

Fig. 3. Strain path dependent behavior of medium dense sand: (a) stress-strain curves, (b) excess pore water pressure versus axial strain curves, (c) effective stress paths, (d) effective stress ratio versus axial strain curves

the undrained path is in between that for a negative (dilative) strain path and a positive (compressive) strain path. This is consistent with previous studies carried out in triaxial cells (Chu et al., 1992; Chu and Lo, 1994; Vaid and Eliadorani, 1998, Chu and Leong, 2001; Lancelot et al., 2004; Sivathayalan and Logeswaran, 2007).

The effective stress paths obtained from the strain path tests are plotted in Fig. 3(c). The Failure Line (FL) obtained from drained compression tests carried out on specimens with similar relative density is also plotted in Fig. 3(c) for comparison. Its slope in the $q-p^{\prime}$ diagram is $\eta_{\mathrm{f}}=1.53$. Except the test with $d \varepsilon_{\mathrm{v}} / d \varepsilon_{1}=-1.0$, all the other paths show a tendency to approach the asymptotic line, called the constant stress ratio line (CSRL) by Chu et al. (2003). This type of behavior had been termed as the asymptotic behavior by Gudehus et al. (1977) to describe a response of soil along proportional stress/strain paths. It can be observed that the larger (i.e., the more positive) the strain increment ratio, the lower the asymptotic stress ratio $\left(q / p^{\prime}\right)_{\text {asy }}$. This can also be seen from the $q / p^{\prime}$ versus $\varepsilon_{1}$ curves shown in Fig. 3(d). However due to shear band formation, strain softening and thus a reduction in $q / p^{\prime}$ occurred in some tests (Figs. 3(a) and (d)). It is also observed that although $\left(q / p^{\prime}\right)_{\text {asy }}$ increases with increasing dilatancy ratio $\left(-d \varepsilon_{\mathrm{v}} / d \varepsilon_{1}\right)$, the $\left(q / p^{\prime}\right)_{\text {asy }}$ approached by the tests with $d \varepsilon_{\mathrm{v}} / d \varepsilon_{1}=-0.4,-0.6$, and -1.0 is about the same value of $\eta_{\max }=1.45$. Therefore, there appears to be a limiting value, $\eta_{\max }$. When $\left(-d \varepsilon_{\mathrm{v}} / d \varepsilon_{1}\right)$ exceeds a certain value, $\left(q / p^{\prime}\right)_{\text {asy }}$ will only reach this limiting value. This observation is again consistent with previous studies carried out in triaxial cells (Topolnicki et al., 1990; Chu et al., 1992, 1996; Vaid and Eliadorani, 1998, Sivathayalan and Logeswaran, 2007).

It should also be pointed out that several strain path tests on medium loose and very loose specimens under plane-strain conditions were conducted by Wanatowski et al. (2008) and the asymptotic behavior was also observed for very loose and medium loose sand.

\section{INSTABILITY BEHAVIOR OF SAND IN STRAIN PATH TESTING}

\section{Very Loose Sand}

The results of the instability test, INSP01, conducted on very loose sand under a strain path controlled condition are presented in Fig. 4 . The specimen was $K_{0}$ consolidated to a mean effective stress of $199 \mathrm{kPa}$. The void ratio after $K_{0}$ consolidation was $e_{\mathrm{c}}=0.898$. Upon reaching point A $\left(q / p^{\prime}=0.88\right)$, the $K_{0}$ condition was changed to a strain path control of $d \varepsilon_{\mathrm{v}} / d \varepsilon_{1}=-0.60$ with the deviator load maintained constant. During the strain path control, the pore water pressure increased gradually (Fig. 4(b)) and the effective stress path moved towards the critical state line (CSL), as shown in Fig. 4(a). The specimen 


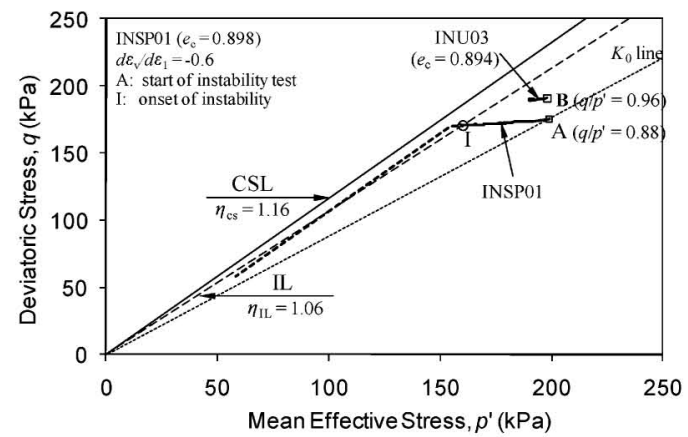

(a)

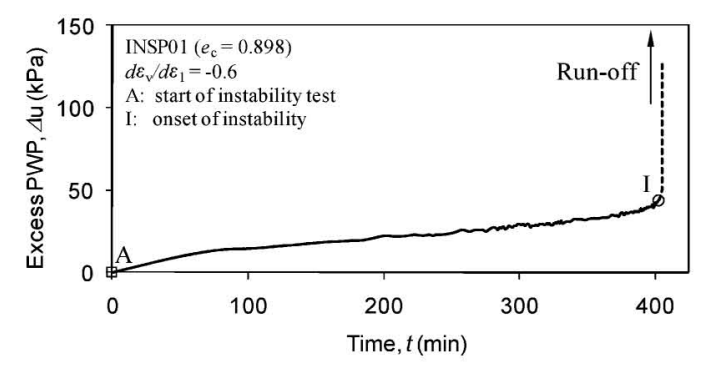

(b)

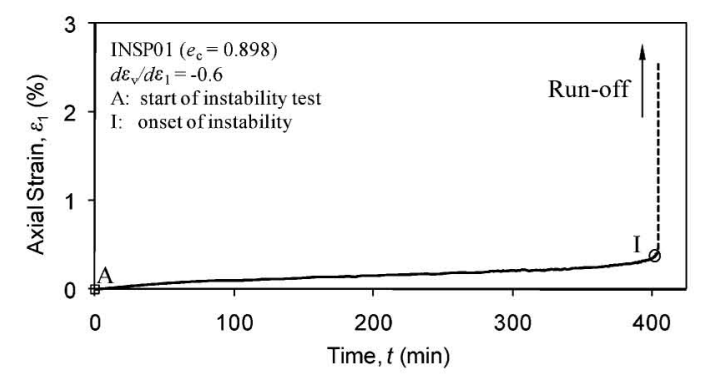

(c)

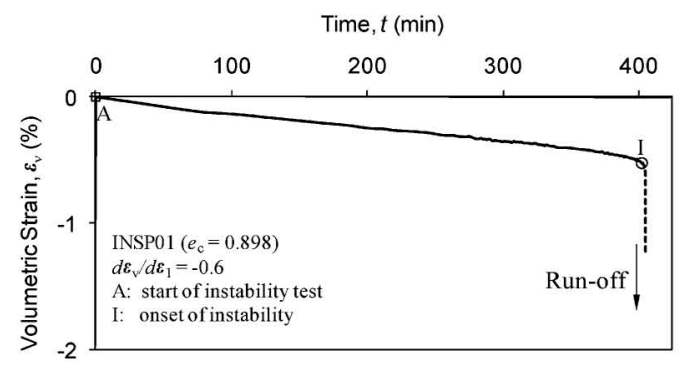

(d)

Fig. 4. Instability behavior of very loose sand in strain path testing: (a) effective stress path; (b) excess pore water pressure versus time curve; (c) axial strain versus time curve; (d) volumetric strain versus time curve

became unstable when the stress state reached point I. At point I, the axial strain and volumetric strain started to accelerate, as shown in Figs. 4(c) and (d). At the same time, the excess pore water pressure also began to increase rapidly (Fig. 4(b)). Therefore, it is evident that instability has occurred at point I. Using point I, the instability line, IL, (Lade, 1992; Chu et al., 2003) can be determined, as shown in Fig. 4(a). The gradient of the instability line (IL), $\eta_{\mathrm{IL}}=1.06$. Since the instability was initiated before the CSL, which is also the failure line (FL) for very loose sand, this is a pre-failure instability.
The specimen physically collapsed after instability has occurred, as in undrained instability tests on loose sand (Lade, 1992, 1993; Leong et al., 2000; Chu et al., 2003, Chu and Wanatowski, 2008) Therefore, the instability in Test INSP01 is the runaway type. It should also be mentioned that there was no visible shear band detected in Test INSP01.

The undrained stress path obtained from Test INU03 (Wanatowski, 2009), conducted on very loose sand $\left(e_{\mathrm{c}}=\right.$ 0.894 ) under an undrained condition, is also plotted in Fig. 4(a) for comparison. Although point B is represented by $q / p^{\prime}=0.96$ which is higher than that at point $\mathrm{A}$ $\left(q / p^{\prime}=0.88\right)$, undrained instability did not occur in Test INU03. Therefore, the specimen in Test INSP01 would also be stable at point $\mathrm{A}$ if an undrained condition was imposed. However, under a strain path control of $d \varepsilon_{\mathrm{v}} / d \varepsilon_{1}$ $=-0.60$, the runaway instability has occurred in Test INSP01.

\section{Medium Loose Sand}

It was shown above that an otherwise stable specimen can exhibit a runaway instability when a dilative strain increment ratio is imposed to it. Another test, INSP02, was carried out on medium loose sand under a strain path controlled condition. The results of Test INSP02 are presented in Fig. 5. As shown in Fig. 5(a), the specimen was first $K_{0}$ consolidated to point $\mathrm{A}\left(q / p^{\prime}=0.96\right)$ and then sheared along a drained path until point $\mathrm{B}\left(q / p^{\prime}=\right.$ 1.23). Upon reaching point $\mathrm{B}$, a strain path of $d \varepsilon_{\mathrm{v}} / d \varepsilon_{1}=$ -0.60 was imposed with the deviator load kept constant.

It can be seen from Figs. 5(b) and (c) that the axial strain and pore water pressure started to accelerate when the stress state reached point I. Thus, instability occurred at point I. As can be seen from the stress paths plotted in Fig. 5(a), the deviatoric stress started to reduce rapidly at point I, where instability occurred. This reduction in $q$ was caused by a large axial strain and a rapid volumetric dilation, as shown in Figs. 5(c) and (d). Using point I, where large plastic strains are developed, the instability line (IL) can be determined. As shown in Fig. 5(a), the instability occurred at the stress point on the instability line (IL) with $\eta_{\mathrm{IL}}=1.27$, that is, before the failure line (FL) with the gradient $\eta_{\mathrm{f}}=1.35$, as determined by drained tests conducted on specimens with the same void ratio (Wanatowski and Chu, 2006). Thus, the instability in Test INSP02 is a pre-failure instability.

After the instability took place in Test INSP02, the specimen physically collapsed, as shown in Fig. 6. Therefore, the instability observed in Test ISP02 is a runaway type. This behavior is similar to the runaway instability observed by Leong et al. (2000) and Chu and Leong (2001) in loose sand under an undrained condition. This shows that a medium loose specimen that exhibits strain hardening behavior under an undrained condition can liquefy like a loose specimen when subjected to a dilative strain path. Similarly to the very loose specimen in Test INSP01, there was no visible shear band in Test INSP02. 


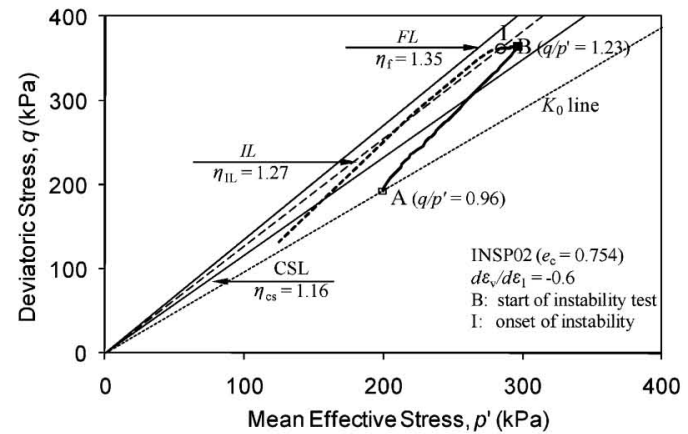

(a)

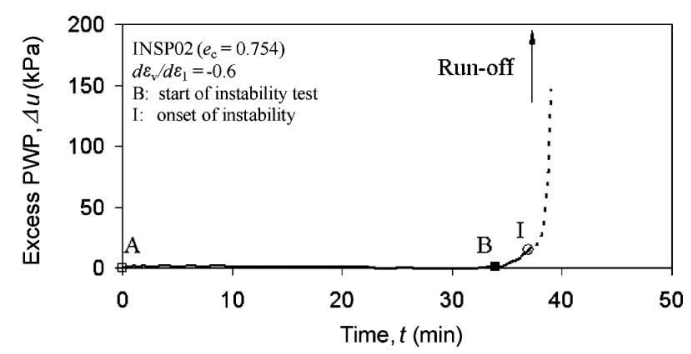

(b)

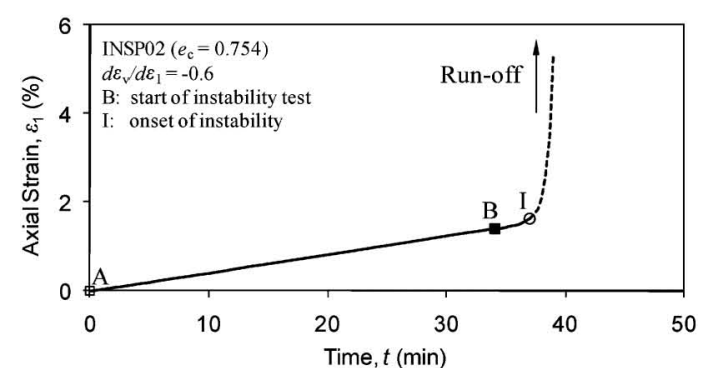

(c)

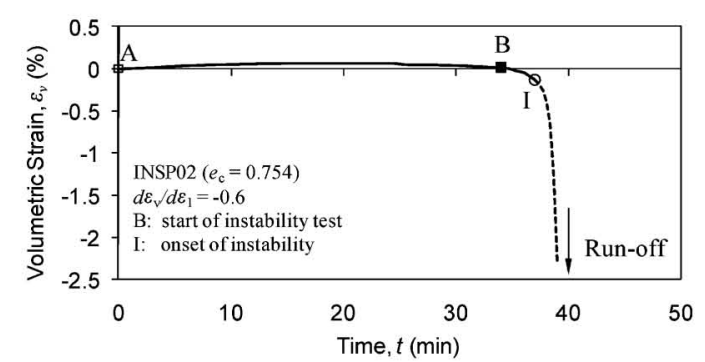

(d)

Fig. 5. Instability behavior of medium loose sand in strain path testing: (a) effective stress path; (b) excess pore water pressure versus time curve; (c) axial strain versus time curve; (d) volumetric strain versus time curve

\section{Medium Dense Sand}

To verify whether runaway type of instability can be observed for medium dense sand, Test INSP06 was carried out. The effective stress path of Test INSP06 is plotted in Fig. 7(a). The critical state line (CSL) and the failure line (FL) obtained from $\mathrm{CK}_{0} D$ tests on comparable void ratios (Wanatowski and $\mathrm{Chu}, 2006$ ) are also shown in Fig. 7(a). The slopes of the CSL and the FL are $\eta_{\mathrm{cs}}=1.16$ and $\eta_{\mathrm{f}}=1.53$, respectively. After the specimen was $K_{0}$ consolidated to point A $\left(q / p^{\prime}=1.06, e_{\mathrm{c}}=0.685\right)$, a strain increment ratio of $d \varepsilon_{\mathrm{v}} / d \varepsilon_{1}=-0.60$ was imposed

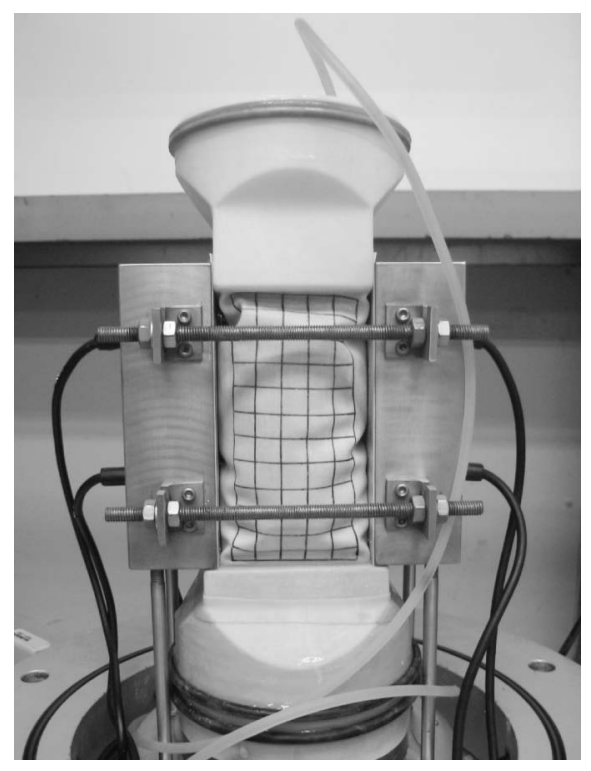

Fig. 6. The specimen in Test INSP02 after the occurrence of runaway instability

while keeping the deviator load constant. Under this strain path, the pore water pressure increased gradually (Fig. 7(b)). It can be seen from Figs. 7(c) and (d) that the axial and volumetric strains developed slowly until a shear band occurred at point SB. The pore water pressure was almost constant before the shear band had occurred (Fig. 7(b)). During this period, the axial strain and the volumetric strain rate increased steadily at a very slow rate of $0.002 \% / \mathrm{min}$ for $\varepsilon_{1}$ and $0.0015 \% / \mathrm{min}$ for $\varepsilon_{\mathrm{v}}$ (Figs. 7(c) and (d)). However, soon after the shear band formation (point SB), the excess pore water pressure shot up (Fig. 7(b)). The axial and volumetric strains increased suddenly (Figs. 7(c) and (d)). The specimen physically collapsed and the runaway instability had occurred at point F. As shown in Fig. 7(a), point F coincides with the failure line (FL) determined by drained tests.

As indicated in Fig. 7, shear bands were observed in strain-path controlled instability plane-strain tests carried out on medium dense sand. However, shear bands were not detected in tests carried out on very loose to medium loose specimens. Although shear band formation in drained and undrained plane-strain compression tests have been observed by a number of researchers (e.g., Cornforth, 1964; Han and Vardoulakis, 1991; Finno et al., 1996; Mokni and Desrues, 1998; Alshibli and Sture, 2000; Desrues and Viggiani, 2004; Wanatowski and Chu, 2006), shear bands in plane-strain instability tests carried out under strain path-controlled conditions have not been studied before.

In order to investigate the effect of shear bands on the instability behavior of sand in plane-strain tests under strain-path controlled conditions, the process of shear band formation has been monitored by taking photographs at a close time interval using a high resolution digital camera. Grid lines were marked on the surface of the specimen facing the camera ( $\sigma_{3}$ plane) to facilitate the ob- 


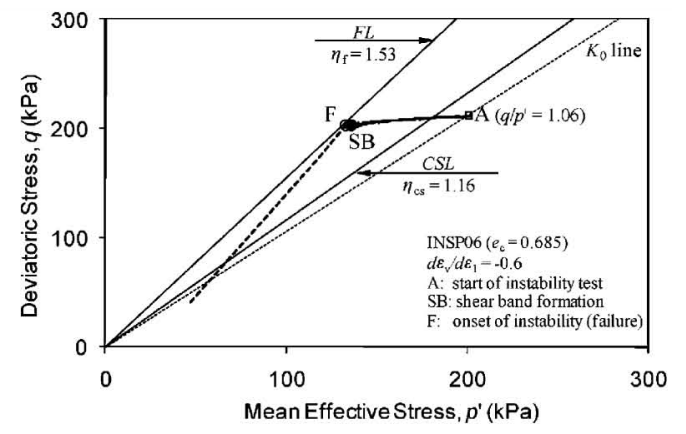

(a)

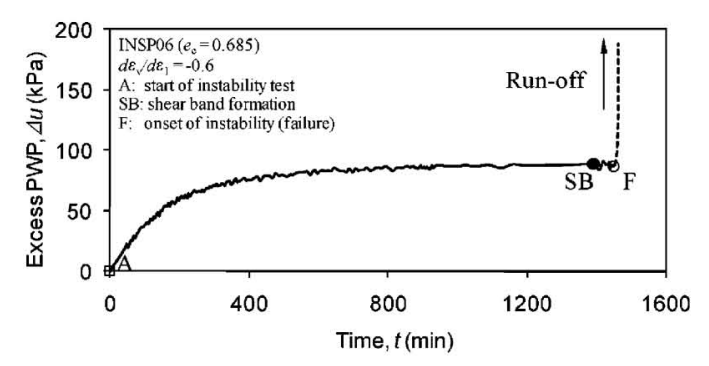

(b)

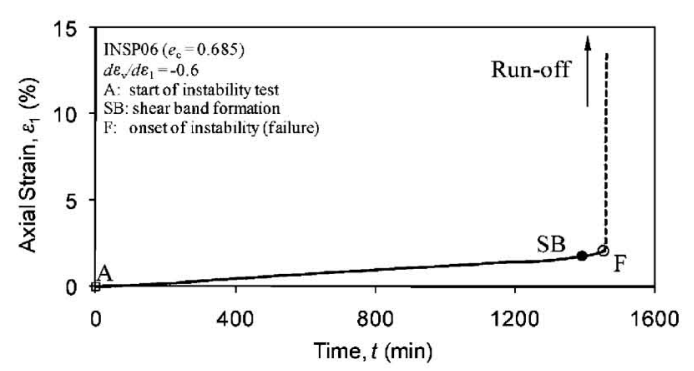

(c)

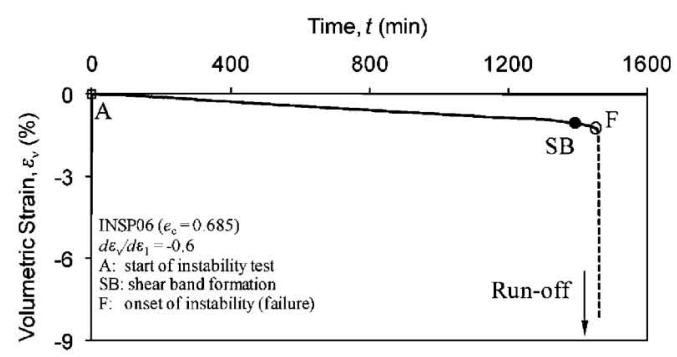

(d)

Fig. 7. Instability behavior of medium dense sand in strain path testing: (a) effective stress path; (b) excess pore water pressure versus time curve; (c) axial strain versus time curve; (d) volumetric strain versus time curve

servation of the shear band. The occurrence of the shear bands was also detected by comparing the $\sigma_{2}-\varepsilon_{1}$ curves obtained from the four individual pressure transducers, a technique discussed in detail by Wanatowski and Chu (2006).

The shear band development in Test INSP06 is shown in Fig. 8. Selected photos around shear band are shown in Fig. 8(a). The $\sigma_{2}$ against time curves obtained from Test INSP06 are plotted in Fig. 8(b). It is seen that the $\sigma_{2}$ values measured by the four individual load cells were almost identical until point $7(\mathrm{O})$. It is indicative that the shear band might have occurred at point $7(\mathrm{O})$. Similarly to the other types of plane-strain tests conducted on medium dense specimens there was no indication of shear band occurrence on the deviatoric stress or effective stress ratio curves, as shown in Fig. 8(c). Furthermore, there was no visible shear band at point 7(O) either (Fig. 8(a)). However, once the shear band was captured by a camera (point 9(B)), the deviatoric stress and $q / p^{\prime}$ ratio decreased significantly, as shown in Fig. 8(b). The excess pore water pressure versus time and axial strain versus time curves obtained from Test INSP06 are shown in Figs. 8(d) and (e) respectively. It is seen that soon after the shear band was fully developed (point 9(B)), both $\Delta u$ and $\varepsilon_{1}$ shot up and the specimen collapsed within a minute. This behavior is typical for all the other instability tests conducted on medium dense sand with dilative strain increment ratio imposed. It can be concluded that the instability in this test is likely caused by the shear band, which occurred in the vicinity of failure. Therefore, the instability in Test INSP06 is a type of on-failure instability.

It needs to be pointed out, however, that an investigation of shear band development was not the main objective of this study. Therefore, techniques such as stereophotogrammetry, computed tomography, or digital image correlation were not used. The observation that the instability in Test INSP06 is likely caused by the shear band is not conclusive. Further study, incorporating more sophisticated methods of shear band detection, is still required to establish whether this type of instability is caused by shear band, or the formation of shear band causes instability. Particularly, an open question remains: do shear bands in sand specimens occur for a certain range of initial densities, a certain range of stress levels, and a certain range of strain increment ratios? This would constitute a separate research task in the future.

\section{DISCUSSIONS}

The experimental data presented in this paper show that runaway instability can occur for very loose to medium dense sand in a constant load test under strain path controlled conditions. Similarly to the instability behavior of granular soils under drained condition (Chu et al., 2003; Wanatowski et al., 2010), the instability behavior of granular soils in strain path testing is also affected by void ratio. It was observed that the higher the void ratio the lower the gradient of the instability line, as shown in Figs. 4, 5, and 7. On the other hand, once instability occurs, the specimen collapses irrespective of the void ratio.

Lade (1992), Chu et al. (2003) and Wanatowski and Chu (2007) have shown that the instability line for very loose sand can be determined by joining the peak points of the effective stress paths obtained under undrained conditions. Furthermore, the constant stress ratio line obtained from undrained tests can be used to predict the occurrence of instability for medium dense sand. Similar method can be used to determine the instability line under 

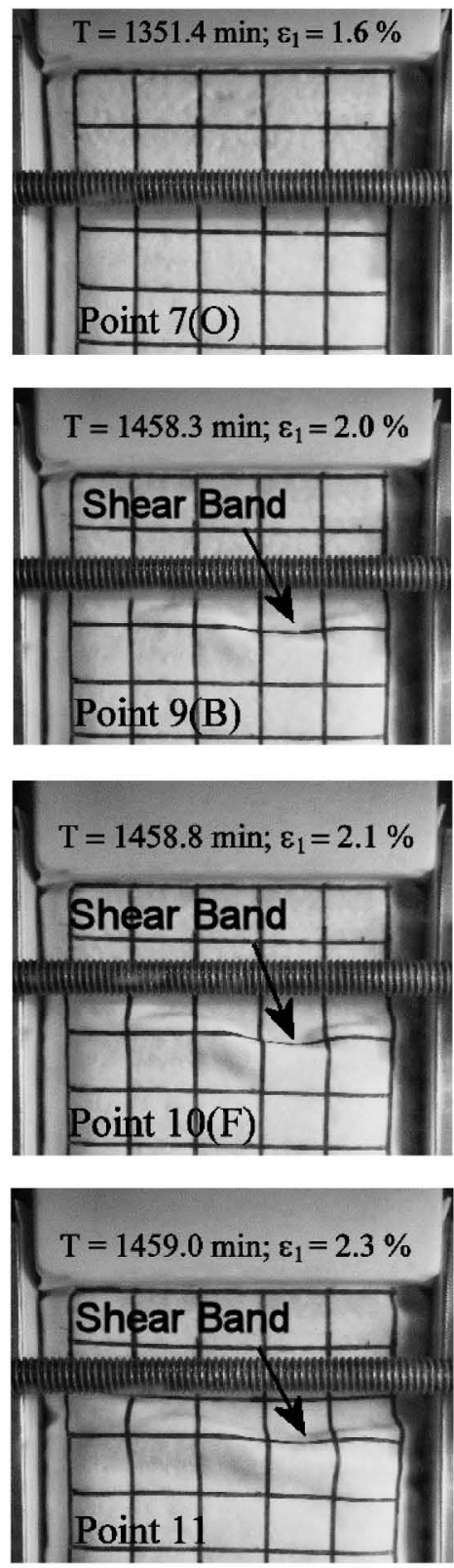

(a)

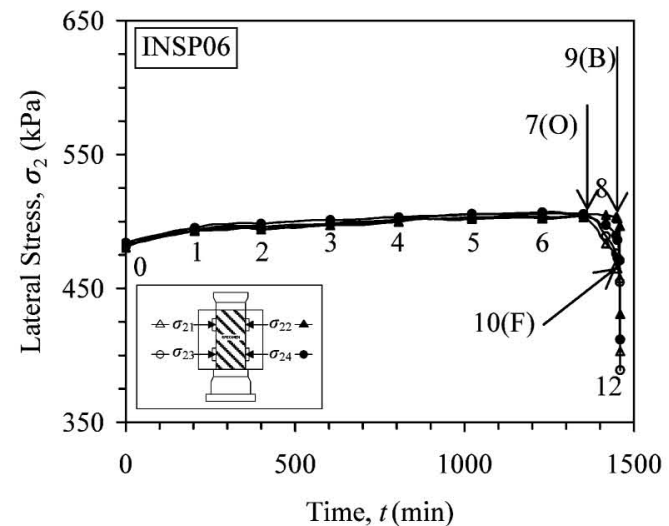

(b)

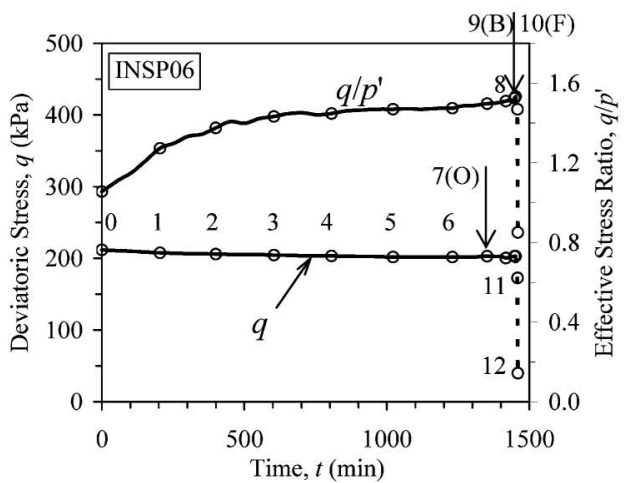

(c)

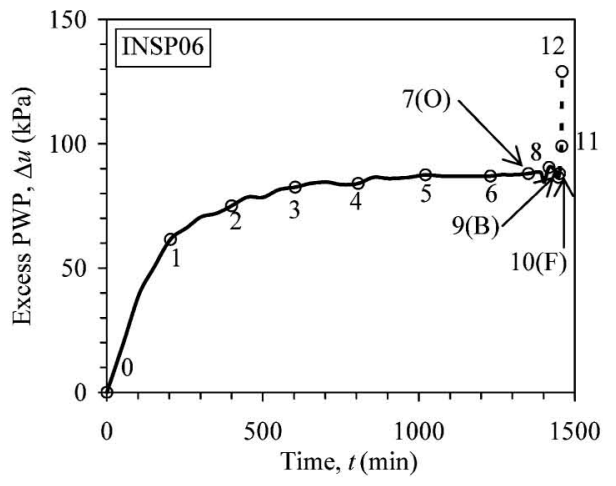

(d)

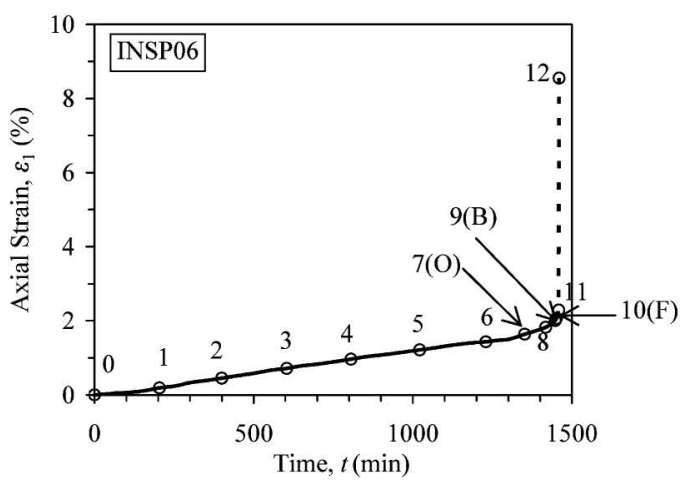

(e)

Fig. 8. Shear band development in Test INSP06: (a) selected photos; (b) $\sigma_{2}$ versus time curves; (c) $q$ versus time and $q / p^{\prime}$ versus time curves; (d) $\Delta u$ versus time curve; (e) $\varepsilon_{1}$ versus time curve

strain path controlled conditions. By conducting $d \varepsilon_{\mathrm{v}} / d \varepsilon_{1}$ $=$ const path triaxial tests at different effective confining pressure, using a deformation-controlled loading mode, a peak stress line (PSL) can be determined.

Figure 9 shows the results of three strain path tests SP10, SP27 and SP28 with $d \varepsilon_{\mathrm{v}} / d \varepsilon_{1}=-0.60$ imposed. The 


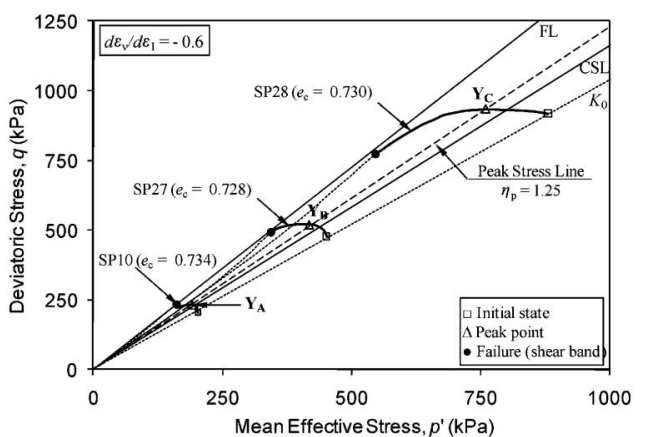

(a)

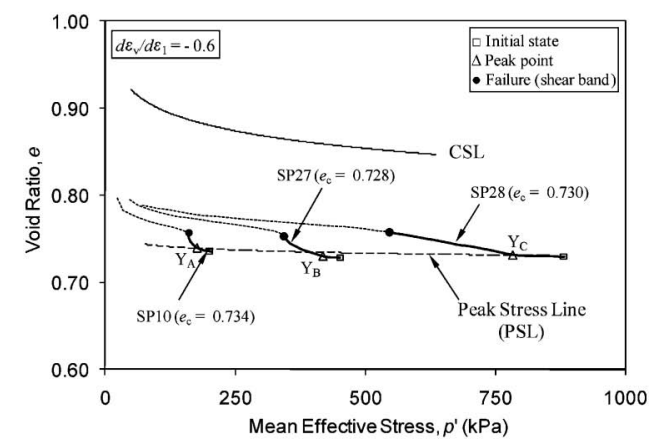

(b)

Fig. 9. The peak stress line determined by $d \varepsilon_{\mathrm{v}} / d \varepsilon_{1}=-0.6$ path tests: (a) $q-p^{\prime}$ plane; (b) $e-p^{\prime}$ plane

void ratios of the specimens SP10, SP27 and SP28 after $K_{0}$ consolidation were $0.734,0.728$ and 0.730 respectively. Strain-softening behavior was observed for all the three specimens, as shown in Fig. 9(a). From the $e-p^{\prime}$ plot presented in Fig. 9(b), it can be seen that plastic yielding occurred at points $\mathrm{Y}_{\mathrm{A}}, \mathrm{Y}_{\mathrm{B}}$ and $\mathrm{Y}_{\mathrm{C}}$ for all the three tests. As shown in Fig. 9(a), these points correspond to the peak of the effective stress paths. By joining these three points with the origin, a peak stress line (PSL) can be established. The PSL has a gradient of $\eta_{\mathrm{p}}=1.25$, as shown in Fig. 9(a). By joining the three yielding points $\mathrm{Y}_{\mathrm{A}}, \mathrm{Y}_{\mathrm{B}}$, and $\mathrm{Y}_{\mathrm{C}}$ together on the $e-p^{\prime}$ plane, the PSL on the $e-p^{\prime}$ plane can also be obtained, as shown in Fig. 9(b).

From the studies on undrained instability behavior of sand that occurs under a load-controlled loading mode, it is known that the instability line is determined by joining the peak points of the undrained stress paths obtained under a deformation-controlled loading mode (Lade, 1992, 1993; Chu et al., 2003; Chu and Wanatowski, 2009). Therefore, the PSL obtained in Fig. 9(a) from strain path tests conducted under a deformation-controlled loading mode could also be the instability line for strain path tests conducted under a load-controlled loading mode.

The slope of the PSL, $\eta_{\mathrm{p}}$, obtained from $d \varepsilon_{\mathrm{v}} / d \varepsilon_{1}=$ -0.6 tests conducted under a deformation-controlled loading mode is plotted versus the void ratio, $e_{\mathrm{c}}$, in Fig. 10. The data obtained from the instability tests conducted with $d \varepsilon_{\mathrm{v}} / d \varepsilon_{1}=-0.6$ controlled are also plotted in Fig. 10 . For each test, a solid symbol indicates the instability behavior coupled with the shear band formation and an

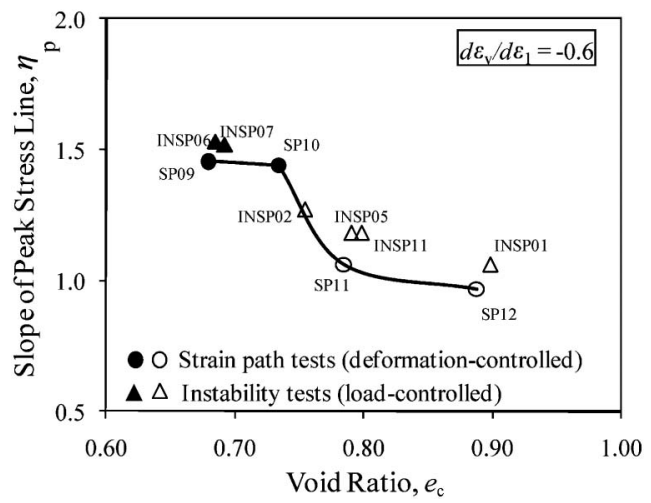

Fig. 10. Relationship between the slope on the peak stress line, $\eta_{\mathrm{p}}$, and void ratio, $e_{\mathrm{c}}$, for $d \varepsilon_{\mathrm{v}} / d \varepsilon_{1}=-0.6$ path tests

open symbol indicates the instability behavior not related to the shear band formation. It can be seen that the slope obtained from the instability tests agrees reasonably well with that determined from strain path tests conducted with the same $d \varepsilon_{\mathrm{v}} / d \varepsilon_{1}$. Therefore, the occurrence of instability in the constant load tests can be predicted by the PSL obtained from the strain path tests, conducted with the same $d \varepsilon_{\mathrm{v}} / d \varepsilon_{1}$. However, triaxial test results obtained by Chu et al. (1993) and Vaid and Eliadorani (1998) have shown that the occurrence of instability is affected not only by the void ratio but also by the strain increment ratio or the drainage conditions imposed.

The influence of strain increment ratio, $d \varepsilon_{\mathrm{v}} / d \varepsilon_{1}$, on the instability behavior of medium loose sand was investigated by conducting two tests, INSP03 $\left(e_{\mathrm{c}}=0.797\right)$ and INSP11 $\left(e_{\mathrm{c}}=0.798\right)$ under the same testing conditions but with a different $\left(d \varepsilon_{\mathrm{v}} / d \varepsilon_{1}\right)_{\mathrm{i}}$ ratio. The strain increment ratio of -0.40 was imposed in Test INSP03, whereas the strain increment ratio of -0.60 was imposed in Test INSP 11 . The results of the two tests are compared in Fig. 11.

From the axial strain versus time curves of the two tests, presented in Fig. 11(c), it can be seen that the axial strains in both tests started to accelerate at points $\mathrm{I}_{3}$ and $I_{11}$. Therefore, instability occurred at points $I_{3}$ and $I_{11}$. Using points $I_{3}$ and $I_{11}$, the instability line for each of the test can be determined on the $q-p^{\prime}$ plane, as shown in Fig. 11(a). It can be seen from Fig. 11(a) that although the constant load tests were started from the same $K_{0}$ consolidation line (point $\mathrm{A}$ or $\mathrm{A}^{\prime}$ ), the two different instability lines were obtained. In test INSP03, the specimen became unstable when the stress path reached the stress state at $\eta_{\mathrm{IL}}=1.25$ (point $\mathrm{I}_{3}$ ). In test INSP11, the specimen became unstable at $\eta_{\mathrm{IL}}=1.19$ (point $\mathrm{I}_{11}$ ). Two separate instability lines were thus obtained, as shown in Fig. 11(a). It can also be observed from Fig. 11(d) that the specimen in Test INSP11 $\left(d \varepsilon_{\mathrm{v}} / d \varepsilon_{1}=-0.6\right)$ exhibits larger volumetric dilation than the specimen in Test INSP03 $\left(d \varepsilon_{\mathrm{v}} / d \varepsilon_{1}=\right.$ -0.4). During the constant load test, the specimen with imposed $d \varepsilon_{\mathrm{v}} / d \varepsilon_{1}=-0.6$ experienced a volumetric dilation of $0.27 \%$, whereas the specimen with $d \varepsilon_{\mathrm{v}} / d \varepsilon_{1}=-0.4$ exhibited a much smaller volumetric dilation of $0.17 \%$. It shows that the plastic yielding in a specimen will occur earlier when more negative $d \varepsilon_{\mathrm{v}} / d \varepsilon_{1}$ is imposed. There- 


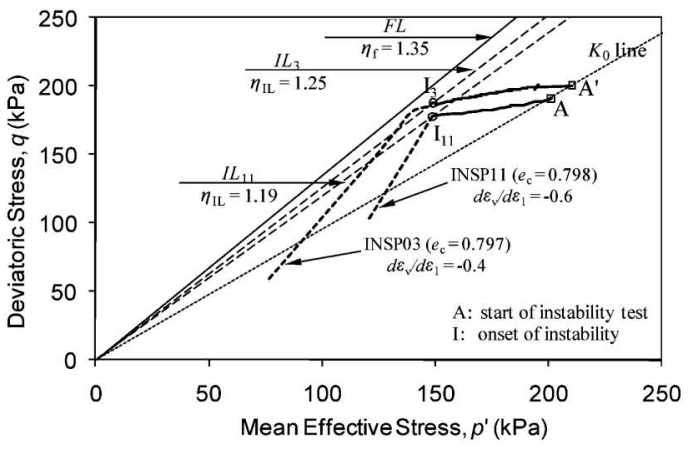

(a)

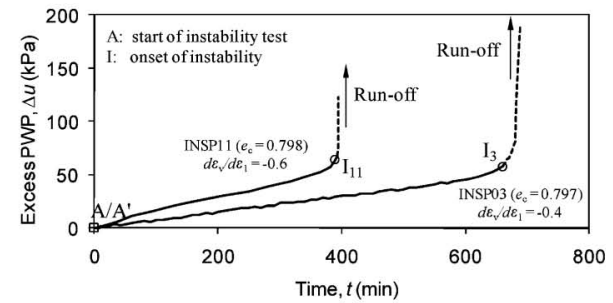

(b)

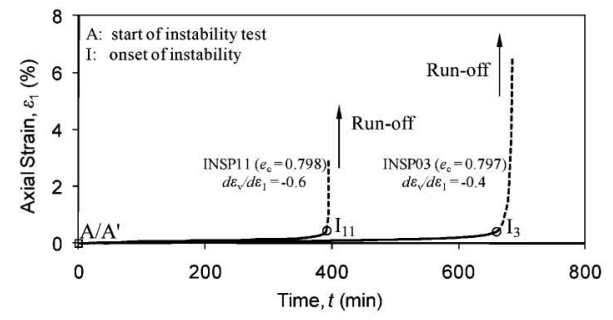

(c)

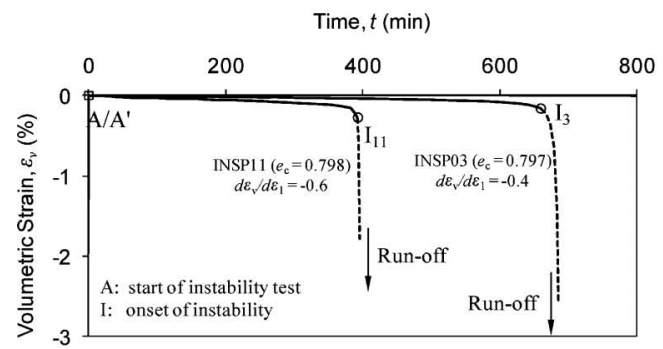

(d)

Fig. 11. Effect of strain increment ratio on the instability of medium loose sand in strain path testing: (a) effective stress paths; (b) excess pore water pressure versus time curve; (c) axial strain versus time curves; (d) volumetric strain versus time curves

fore, the specimen in Test INSP11 became unstable faster than the specimen in Test INSP03 (Fig. 11(c)). The specimen in Test INSP11 $\left(d \varepsilon_{\mathrm{v}} / d \varepsilon_{1}=-0.6\right)$ took a much shorter time $(\approx 392$ minutes) than the specimen in test INSP03 $\left(d \varepsilon_{\mathrm{v}} / d \varepsilon_{1}=-0.4 ; \approx 660\right.$ minutes $)$ to reach the stress state at point $\mathrm{I}_{11}$ or $\mathrm{I}_{3}$ where instability occurred. At the same time, it can be seen that both specimens experienced similar axial strains during the constant load tests. The specimen with imposed $d \varepsilon_{\mathrm{v}} / d \varepsilon_{1}=-0.6$ experienced an axial strain of $0.45 \%$. For the specimen with imposed $d \varepsilon_{\mathrm{v}} / d \varepsilon_{1}$ $=-0.4$, an axial strain of $0.42 \%$ was observed. The excess pore water pressures developed in the two tests were also similar $(\Delta u=60-66 \mathrm{kPa})$ before the occurrence of instability, as shown in Fig. 11(b). After the onset of

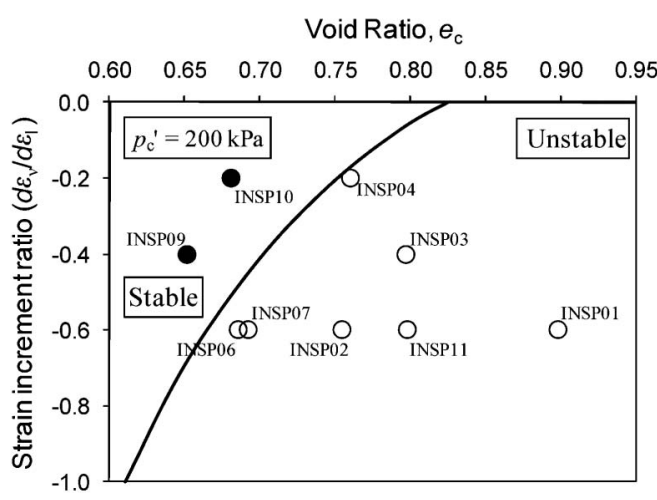

Fig. 12. Instability boundary under plane-strain conditions for $p_{\mathrm{c}}^{\prime}=$ $200 \mathrm{kPa}$

instability, the axial deformations and pore water pressures in both tests shot up and the specimens physically collapsed.

From the experimental results presented above, it can be seen that the strain increment ratio affects the instability behavior of sand in strain path testing under planestrain conditions. This is consistent with observations made under axisymmetric conditions (Chu et al., 1993; Vaid and Eliadorani, 1998; Lancelot et al., 2004; Sivathayalan and Logeswaran, 2007). It was shown that the more dilative the $d \varepsilon_{\mathrm{v}} / d \varepsilon_{1}$ imposed to the specimen, the higher the tendency for instability to occur. This is because when a $d \varepsilon_{\mathrm{v}} / d \varepsilon_{1}$ larger than the dilatancy ratio of the soil is imposed, the pore water pressure will increase. This in turn leads to a decrease in effective confining stress and causes instability when the instability line is crossed.

Since the occurrence of instability in strain path testing is influenced by both, the void ratio and the strain increment ratio, there is an instability boundary on the $e_{\mathrm{c}}$ versus $\left(d \varepsilon_{\mathrm{v}} / d \varepsilon_{1}\right)_{\text {i }}$ plane, which represents the critical conditions for instability to occur. The initial states of the instability tests conducted under plane-strain conditions with $d \varepsilon_{\mathrm{v}} / d \varepsilon_{1}=-0.6$ imposed to specimens are plotted in Fig. 12. It can be seen that the two stable points are on the left top corner, that is, where $\left(d \varepsilon_{\mathrm{v}} / d \varepsilon_{1}\right)_{\mathrm{i}}$ is larger (less negative) or where the void ratio is smaller. There appears to be a boundary that separates the $e_{\mathrm{c}}$ versus $\left(d \varepsilon_{\mathrm{v}} / d \varepsilon_{1}\right)_{\mathrm{i}}$ plane into a stable and an unstable zone, as shown in Fig. 12. This is similar to the boundary for strain softening, reported by Wanatowski et al. (2008). The similarity indicates that the condition for the occurrence of instability is analogous to that for the occurrence of strain softening. Similar observations were also made by $\mathrm{Chu}$ and Leong (2001) under axisymmetric conditions. They have concluded that if strain softening occurs for a soil specimen under a deformation-controlled loading mode, instability will occur for the same specimen under a load-controlled loading mode and vice-versa. It should be pointed out that the instability boundary in Fig. 12 is determined only for $p_{\mathrm{c}}^{\prime}=200 \mathrm{kPa}$. However, the effective confining stress also affects the stress-strain behavior and volumetric response of granular materials. In particular the influence of the effective confining stress on the value of $d \varepsilon_{\mathrm{v}} / d \varepsilon_{1}$ at 
failure has been established for a number of granular materials (Lee and Seed, 1967; Castro, 1969; Wu, 1990; Chu et al., 1993). Generally, it was observed that the higher effective confining stress, the less dilative response of the sand at failure. Therefore, the higher the effective confining stress, the less dilative a value of $\left(d \varepsilon_{\mathrm{v}} / d \varepsilon_{1}\right)_{\mathrm{i}}$ is needed to trigger instability. In other words, for the same strain increment ratio imposed to the specimen, the higher confining stress results in the higher tendency for instability to occur. If the influence of $p_{c}^{\prime}$ is taken into consideration, a critical surface for the occurrence of instability can be formed in the $p_{\mathrm{c}}^{\prime}-e_{\mathrm{c}}-\left(-d \varepsilon_{\mathrm{v}} / d \varepsilon_{1}\right)_{\mathrm{i}}$ space. The critical surface would illustrate the mutual influence of $p_{\mathrm{c}}^{\prime}, e_{\mathrm{c}}$, and $d \varepsilon_{\mathrm{v}} / d \varepsilon_{1}$ on the occurrence of instability under plane-strain conditions. However, it should be pointed out that a number of tests with various initial conditions are needed to determine the critical surface for instability (Chu et al., 1993; Wanatowski, 2009).

\section{CONCLUSIONS}

The results of constant load tests conducted under strain path controlled conditions using the plane-strain apparatus are presented and compared in this study. To authors' knowledge such strain path tests have been carried out by other researchers only under axisymmetric conditions. Based on the experimental results presented, the following conclusions can be drawn:

1) The stress-strain behavior of sand under planestrain conditions is strain path dependent. When the strain increment ratio imposed, $\left(d \varepsilon_{\mathrm{v}} / d \varepsilon_{1}\right)_{\mathrm{i}}$, is larger (i.e., more positive) than the threshold value, strain hardening behavior will prevail. On the other hand, when the $\left(d \varepsilon_{\mathrm{v}} / d \varepsilon_{1}\right)_{\mathrm{i}}$ is smaller (i.e., more negative) than the threshold value, strain softening will occurs. This is consistent with the observations made for axisymmetric conditions based on triaxial test results (Chu et al., 1993, 1996; Vaid and Eliadorani, 1998; Lancelot et al., 2004; Sivathayalan and Logeswaran, 2007).

2) A runaway type of instability can occur even for medium dense sand when a constant load test is conducted under a strain path controlled condition. This type of instability is characterized by a sudden increase in the axial strain rate and pore water pressure. Once the runaway instability occurs the specimen physically collapses and the test is no longer controllable. Similarly to the condition for the occurrence of strain softening, a strain increment ratio imposed to a specimen has to be adequately low (i.e., negative) to generate the pore water pressure. The occurrence of this type of instability is associated with the increase in pore water pressure. Therefore, the increase in pore water pressure is the necessary condition for the occurrence of this type of instability.

3) The instability line obtained from strain path tests under constant load conditions coincides with the peak stress line obtained from strain path tests con- ducted with the same $d \varepsilon_{\mathrm{v}} / d \varepsilon_{1}$ under a deformationcontrolled loading mode. This suggests that the peak stress line can be used to predict the occurrence of instability under strain path controlled conditions. The framework of instability line established in triaxial tests under undrained conditions can therefore be extended into plane-strain and more general drainage conditions. This is very important from practical point of view because plane-strain conditions with simultaneous change in volume and pore water pressure are the most realistic in sandy slopes.

4) The occurrence of pre-failure instability under plane-strain conditions is affected by the void ratio and the strain increment ratio. The higher the void ratio and the smaller the strain increment ratio, the greater tendency for instability to occur. This is consistent with the findings established by $\mathrm{Chu}$ et al. (1993) under axisymmetric conditions. However, there are also differences in the instability behavior on dilative sand tested in triaxial and plane-strain apparatuses. In strain path-controlled instability tests carried out on dense sand under axisymmetric conditions, shear band does not occur either before or after the occurrence of the instability, as shown by Chu et al. (1993) and Chu and Leong (2001) whereas under plane-strain conditions, shear band occurs slightly before the onset of instability.

5) Instability in strain path-controlled tests on medium dense sand is likely caused by the shear band, which occurred in the vicinity of failure. Therefore, it is on-failure type of instability. However, this observation is not conclusive and further study is required to establish whether instability is caused by shear band, or the formation of shear band causes instability. It also needs to be determined whether shear bands in sand specimens occur for a certain range of initial densities, stress levels and strain increment ratios. This will constitute a separate research task in the future.

\section{REFERENCES}

1) Adalier, K. and Elgamal, A.-W. (2002): Seismic response of adjacent dense and loose saturated sand columns, Soil Dynamics and Earthquake Engineering, 22, 115-127.

2) Alshibli, A. K. and Sture, S. (2000): Shear band formation in plane strain experiments of sand, Journal of Geotechnical and Geoenvironmental Engineering, ASCE, 126(6), 495-503.

3) ASTM, Standard D-2487: Standard practice for classification of soils for engineering purposes (Unified Soil Classification System), Annual Book of ASTM Standards, ASTM International, West Conshohocken, PA, 4(8), 249-260.

4) ASTM, Standard D-4253: Standard test methods for maximum index density and unit weight of soils using a vibratory table, Annual Book of ASTM Standards, ASTM International, West Conshohocken, PA, 4(8), 556-570.

5) ASTM, Standard D-4254: Standard test methods for minimum index density and unit weight of soils and calculation of relative density, Annual Book of ASTM Standards, ASTM International, West Conshohocken, PA, 4(8), 571-579.

6) Castro, G. (1969): Liquefaction of sands, Harvard Soil Mech. S- 
eries No. 81, Harvard University, Cambridge, Mass.

7) Chu, J. and Lo, S.-C. R. (1991): On the implementation of strain path testing, Proc. the 10th European Conference on Soil Mechanics, Florence, 1, 53-56.

8) Chu, J., Lo, S.-C. R. and Lee, I. K. (1992): Strain softening behavior of a granular soil in strain path testing, Journal of Geotechnical Engineering, ASCE, 118(2), 191-208.

9) Chu, J., Lo, S.-C. R. and Lee, I. K. (1993): Instability of granular soils under strain path testing, Journal of Geotechnical Engineering, ASCE, 119(5), 874-892.

10) Chu, J. and Lo, S.-C. R. (1994): Asymptotic behaviour of a granular soil in strain path testing, Géotechnique, 44(1), 65-82.

11) Chu, J., Lo, S.-C. R. and Lee, I. K. (1996): Strain softening and shear band formation of sand in multi-axial testing, Géotechnique, 46(1), 63-82.

12) Chu, J. and Leong, W. K. (2001): Pre-failure strain softening and pre-failure instability of sand: a comparative study, Géotechnique, 51(4): 311-321.

13) Chu, J., Leroueil, S. and Leong, W. K. (2003): Unstable behaviour of sand and its implication for slope stability, Canadian Geotechnical Journal, 40, 873-885.

14) Chu, J. and Wanatowski, D. (2008): Instability conditions of loose sand in plane-strain, Journal of Geotechnical and Geoenvironmental Engineering, ASCE, 134(1): 136-142.

15) Chu, J. and Wanatowski, D. (2009): Effect of loading mode on strain softening and instability behavior of sand in plane-strain tests, Journal of Geotechnical and Geoenvironmental Engineering, ASCE, 135(1), 108-120.

16) Cornforth, D. H. (1964): Some experiments on the influence of strain conditions on the strength of sand, Géotechnique, 14(2), 143-167.

17) Desrues, J. and Viggiani, G. (2004): Strain localization in sand: An overview of the experimental results obtained in Grenoble using stereophotogrammetry, International Journal for Numerical and Analytical Methods in Geomechanics, 28(4), 279-321.

18) Eckersley, J. D. (1985): Flowslides in stockpiled coal, Engineering Geology, 22, 13-22.

19) Finno, R. J., Harris, W. W. and Viggiani, G. (1996): Strain localization and undrained steady state of sand, Journal of Geotechnical Engineering, ASCE, 122(6), 462-473.

20) Gudehus, G., Goldscheider, M. and Winter, H. (1977): Mechanical properties of sand and clay and numerical integration methods: some sources of errors and bounds of accuracy, Finite Elements in Geomechanics, (ed. by G. Gudehus), London-New York, Wileyand Sons, 121-150.

21) Han, C. and Vardoulakis, I. G. (1991): Plane-strain compression experiments on water-saturated fine-grained sand, Géotechnique, 41(1), 49-78.

22) Ladd, R. S. (1978): Preparing test specimens using undercompaction, Geotechnical Testing Journal, ASTM, 1(1), 16-23.

23) Lade, P. V., Nelson, R. B. and Ito, Y. M. (1988): Instability of granular materials with nonassociated flow, Journal of Engineering Mechanics, ASCE, 114(12), 2173-2191.

24) Lade, P. V. and Pradel, D. (1990): Instability and plastic flow of soils. I: experimental observations, Journal of Engineering Mechanics, ASCE, 116(11), 2532-2550.

25) Lade, P. V. (1992): Static instability and liquefaction of loose fine sandy slopes, Journal of Geotechnical Engineering, ASCE, 118(1), 51-71.

26) Lade, P. V. (1993): Initiation of static instability in the submarine Nerlerk Berm, Canadian Geotechnical Journal, 30, 895-904.

27) Lancelot, L., Shahrour, I. and Al Mahmoud, M. (2004), Instability and static liquefaction on proportional strain paths for sand at low stresses, Journal of Engineering Mechanics, ASCE, 130(11), $1365-1372$.

28) Lee, K. L. and Seed, H. B. (1967): Drained strength characteristics of sand, Journal of Soil Mechanics and Foundation Engineering Division, ASCE, 93(6), 117-141.

29) Leong, W. K., Chu, J. and Teh, C. I. (2000): Liquefaction and instability of a granular fill material, Geotechnical Testing Journal, ASTM, 23(2), 178-192.

30) Lo, S.-C. R., Chu, J. and Lee, I. K. (1989): A technique for reducing membrane penetration and bedding errors, Geotechnical Testing Journal, ASTM, 12(4), 311-316.

31) Lo, S.-C. R. and Chu, J. (1991): The measurement of $K_{0}$ by triaxial strain path testing, Soils and Foundation, 31(2), 181-187.

32) Mokni, M. and Desrues, J. (1998): Strain localisation measurements in undrained plane-strain biaxial tests on Hostun RF sand, Mechanics of Cohesive-Frictional Materials, 4(4), 419-441.

33) National Research Council (1985): Liquefaction of Soils during Earthquakes, National Academies Press, Washington DC.

34) Olson, S. M., Stark, T. D., Walton, W. H. and Castro, G. (2000): 1907 static liquefaction flow failure of the North Dike of Wachusett Dam, Journal of Geotechnical and Geoenvironmental Engineering, ASCE, 126(12), 1184-1193.

35) Rowe, P. W. and Barden, L. (1964): Importance of free ends in triaxial testing, Journal of the Soil Mechanics and Foundations Division, ASCE, 90(1), 1-15.

36) Sento, N., Kazama, M., Uzuoka, R., Ohmura, H. and Ishimaru, M. (2004): Possibility of postliquefaction flow failure due to seepage, Journal of Geotechnical and Geoenvironmental Engineering, ASCE, 129(8), 727-737.

37) Sivathayalan, S. and Logeswaran, P. (2007): Behaviour of sands under generalized drainage conditions, Canadian Geotechnical Journal, 44, 138-150.

38) Tatsuoka, F., Sakamoto, M., Kawamura, T. and Fukushima, S. (1986): Strength and deformation characteristics of sand in plane strain compression at extremely low pressures, Soils and Foundations, 26(1), 65-84.

39) Topolnicki, M., Gudehus, G. and Mazurkiewicz, B. K. (1990): Observed stress-strain behaviour of remoulded saturated clay under plane-strain conditions, Géotechnique, 42(2), 155-187.

40) Torrey, V. H. and Weaver, F. J. (1984): Flow failures in Mississippi riverbanks, Proc. of the 3rd International Symposium on Landslides, Toronto, 2, 335-360.

41) Vaid, Y. P. and Eliadorani, A. (1998): Instability and liquefaction of granular soils under undrained and partially drained states, Canadian Geotechnical Journal, 35, 1053-1062.

42) Wanatowski, D. and Chu, J. (2006): Stress-strain behaviour of a granular fill measured by a new plane-strain apparatus, Geotechical Testing Journal, ASTM, 29(2), 149-157.

43) Wanatowski, D. and Chu, J. (2007): Static liquefaction of sand in plane-strain, Canadian Geotechnical Journal, 44(3), 299-313.

44) Wanatowski, D., Chu, J. and Lo, R. S-C. (2008): Strain softening behaviour of sand in strain path testing under plane-strain conditions, Acta Geotechnica, 3(2), 99-114.

45) Wanatowski, D. (2009): Strain Softening and Instability of Sand, VDM Verlag.

46) Wanatowski, D., Chu, J. and Loke, W. L. (2010): Drained instability of sand in plane-strain, Canadian Geotechnical Journal, 47, 400-412.

47) Wang, Q. and Lade, P. V. (2001): Shear banding in true triaxial tests and its effect on failure in sand, Journal of Engineering Mechanics, ASCE, 127(8), 754-761.

48) Wu, W. (1990): Discussion of 'Behaviour of very loose sand in triaxial compression test', Canadian Geotechnical Journal, 27, 159-162.

49) Yasin, S. J. M., Umetsu, K., Tatsuoka, F., Arthur, J. R. F. and Dunstan, T. (1999): Plane-strain strength and deformation of sands affected by batch variations and different apparatus types, Geotechnical Testing Journal, ASTM, 22(1), 80-100. 